\title{
CoCrMo alloy treated by floating potential plasma assisted nitriding and plasma based ion implantation: Influence of the hydrogen content and of the ion energy on the nitrogen incorporation
}

\author{
L. Pichon ${ }^{\mathrm{a}, *}$, S. Okur ${ }^{\mathrm{b}}$, O. Öztürk ${ }^{\mathrm{b}}$, J.P. Rivière ${ }^{\mathrm{a}}$, M. Drouet ${ }^{\mathrm{a}}$ \\ a Laboratoire de Physique des Matériaux (PhyMat), UMR 6630-CNRS, Université de Poitiers, SP2MI, Boulevard Pierre et Marie Curie BP 30179, \\ 86962 Futuroscope Chasseneuil Cedex, France \\ b Department of Physics - Izmir Institute of Technology, Urla 35430, Izmir, Turkey
}

\section{A R T I C L E I N F O}

Available online 6 February 2010

\section{Keywords:}

Cobalt-chromium-molybdenum alloy

Expanded austenite structure

R.F. plasma nitriding

Plasma based ion implantation

\begin{abstract}
A B S T R A C T
Nitriding was performed on a medical grade CoCrMo alloy at $400{ }^{\circ} \mathrm{C}$ in $\mathrm{N}_{2}$ or $\mathrm{N}_{2}-\mathrm{H}_{2}$ atmosphere at a working pressure of $0.84 \mathrm{~Pa}$ for $2 \mathrm{~h}$. Various surface treatment techniques were used to incorporate nitrogen into the CoCrMo alloy: without any plasma assistance, by floating potential radio-frequency plasma assisted nitriding (FPPAN), by plasma based ion implantation (PBII) with several high voltage accelerations (up to $20 \mathrm{kV}$ ). Without plasma activation, no nitrogen is incorporated in the CoCrMo. On the contrary, all the plasma or PBII treated samples show the formation of a nitrogen-rich f.c.c. $\gamma_{\mathrm{N}}$ phase. The layer nitrided over few microns has a nitrogen composition ranging from 30 at.\% to about 20 at.\% near the nitrided layer-substrate interface, with an enhanced surface microhardness. Hydrogen is found to enhance the nitriding efficiency. Without hydrogen, a high voltage polarization provides a supplementary amount of implanted nitrogen available for further diffusion and the sputtering of the surface passive oxide. So, with limited high voltages, thicker layers with higher amounts of nitrogen can be achieved by PBII compared to plasma nitriding. However, with higher voltages, the sputtering becomes too important and the nitride layer is thinner.
\end{abstract}

(c) 2010 Elsevier B.V. All rights reserved.

\section{Introduction}

Surface treatments are widely employed for enhancement of the biomaterial performances in order to improve the mechanical properties (e.g. toughness, hardness, fatigue or wear resistance) or corrosion resistance of the material. The $\mathrm{CoCr}$ alloys show interesting yield strength and elastic modulus as regards to their orthopaedic prosthesis applications [1]. Moreover, with about 30\% of chromium, it exhibits a very high resistance to corrosion. With molybdenum addition (5-10 wt.\%), the corrosion is almost avoided in organic substances or with sulphuric acid [2]. However, when coupling different solicitations (as wear or fretting and corrosion), the protective passive layer of chromium oxide is no more sufficient to protect it from catastrophic wear and release of metallic (nano-) particles in the body [3]. They may then act as wear third body, leading to a more pronounced degradation of the metallic prosthesis or its UHMWPE counterpart, or poison the human body fluid, leading to various cell necrosis $[4,5]$.

Few studies report the treatments of CoCrMo alloys by means of ion implantation [6-8], plasma nitriding [9-13] or plasma based ion

\footnotetext{
* Corresponding author. Tel.: + 335494967 48; fax: + 33549496692 . E-mail address: luc.pichon@univ-poitiers.fr (L. Pichon).
}

implantation (PBII) [13-16]. In order to conserve the intrinsic good corrosion resistance, the nitriding has to avoid $\mathrm{CrN}$ precipitates or layer formation. Therefore, moderate temperatures around $400{ }^{\circ} \mathrm{C}$ are preferred because they lead to a metastable f.c.c. $\gamma_{\mathrm{N}}$ phase, by insertion of nitrogen in the initial f.c.c. $\gamma$ phase, similar to the one obtained with stainless steel nitriding. Although these surface treatment methods are found to be profitable for wear resistance $[9,11]$, the cobalt ion release seems to be increased by the treatments compared to the initial substrate [7]. By increasing the temperature (600 to $800{ }^{\circ} \mathrm{C}$ ), $\mathrm{CrN}$ and $\mathrm{Cr}_{2} \mathrm{~N}$ are detected by X-ray diffraction. If the wear resistance properties are usually enhanced, the corrosion resistance is then degraded because of the lack of chromium in the alloy to form a passive oxide $[9,11]$.

This work is more focused on the mechanism(s) of nitrogen incorporation in the CoCrMo alloy, depending on the nitriding parameters, and on the consequences on the nitrided case obtained. The role of the hydrogen in the plasma-surface interaction is discussed in comparison with the surface activation by means of plasma based ion implantation (PBII) with pure nitrogen plasma. Many works focus on the nitriding mechanisms of the stainless steel and on the modelisation of the $\gamma_{\mathrm{N}}$ layer growth [17-22]. The profiles of nitrogen, with a very high concentration slightly decreasing in the $\gamma_{\mathrm{N}}$ layer and followed by a sharp decrease and a tail in the bulk, is not coherent with a simple diffusion-limited incorporation (erfc shape). A 
mechanism involving the trapping-detrapping of nitrogen on $\mathrm{Cr}$ atoms was proposed to explain the high level of nitrogen in the $\gamma_{\mathrm{N}}$ layer and the drop of concentration underneath. Christiansen et al. [22] combined the $\mathrm{Cr}$ trapping effect with a diffusion coefficient dependant on the nitrogen concentration (this dependence can be attributed to the residual stress in the layer too) and an evolution of the concentration of the nitrogen absorbed at the surface.

\section{Experimental}

The compositions of the two medical grade CoCrMo alloys (called D15 and D30) are presented in Table 1. From the "D30" (resp. "D15") alloy, cylindrical discs with a thickness of $4 \mathrm{~mm}$ (resp. $3 \mathrm{~mm}$ ) and a diameter of $30 \mathrm{~mm}$ (resp. $15 \mathrm{~mm}$ ) were mechanically polished to mirror-like quality with a final mean surface roughness ( $\mathrm{Ra}$ ) of about $6 \mathrm{~nm}$. Before introduction in the nitriding reactor, all samples were cleaned by an ultra-sonic bath of acetone followed by an ultra-sonic bath of ethanol and finally dried with nitrogen flush.

The nitriding reactor, already presented in details elsewhere [23], consists of a $2.5 \mathrm{~m}$ long and $18 \mathrm{~cm}$ diameter quartz tube pumped down to a base pressure of $5 \cdot 10^{-4} \mathrm{~Pa}$ by a turbomolecular pump. The nitriding working pressure was regulated by a gate valve at $6.3 \mathrm{mTorr}$ $(0.84 \mathrm{~Pa})$ with pure nitrogen (delivered at $50 \mathrm{sccm}$ by mass flowmeter) or with a mixture of nitrogen $(30 \mathrm{sccm})$ and hydrogen $(20 \mathrm{sccm})$. At the gas introduction side of the reactor, the plasma was generated with an external capacitively coupled $13.56 \mathrm{MHz}$ generator, with a forward power of $700 \mathrm{~W}$. The sample was mounted on the electrode arm, roughly to a place in the middle of the tube, and was connected via a feedthrough at the other side of the tube, to the high voltage pulse transistorized generator. As the sample surface temperature is highly dependent on the PBII conditions, the temperature was continuously measured with a thermocouple placed just behind the sample and was adjusted to around $400{ }^{\circ} \mathrm{C}$ by regulating the power of the surrounding cylindrical 3 zones furnace and the PBII parameters. The required parameters (furnace power, pulse length and repetition frequency) were roughly determined by a previous calibration procedure for each high voltage and were continuously slightly adjusted during the treatment to keep the wanted temperature and to obtain the same final nitrogen dose for all samples. So all the D30 PBII samples were nitrided for $2 \mathrm{~h}$, with different high voltages ranging from -5 to $-20 \mathrm{kV}$, but with almost the same total nitrogen dose (7 to $10 \mathrm{E} 17 \mathrm{~N}$ atoms $/ \mathrm{cm}^{2}$ depending on the sample) and with a temperature of about $400+/-20^{\circ} \mathrm{C}$. To evidence the influence of the plasma presence, of the high voltage, and of hydrogen, some other nitriding experiments were performed on D15 or D30 samples: without using a high voltage pulse (the sample potential was measured to be $-20 \mathrm{~V}=$ $-0.02 \mathrm{kV}$ ); without plasma; with hydrogen; or with the sample placed in the tube at floating potential (Floating Potential Plasma Assisted Nitriding: FPPAN).

The samples were characterized by X-ray $\left(\mathrm{CuK}_{\alpha}\right)$ diffraction in the Bragg-Brentano geometry $(\theta-2 \theta)$ on a D8-Bruker diffractometer. Quantified chemical profiles were realized by Radio-Frequency Glow Discharge Optical Emission Spectrometry (GDOES) on a Horiba-JobinYvon GD profiler. Surface microhardness was determined on a Shimatsu Vickers microhardness tester with loads from 25 to $1000 \mathrm{~g}$. The indent depth was varying from one micron to a few tens of microns depending on the load and on the microhardness of the sample. The surface roughness was measured with an interferometry profilometer Talysurf CCI 6000.

\section{Results}

\subsection{Microhardness measurements}

Fig. 1 presents the apparent surface Vickers microhardness improvement, relative to the initial CoCrMo one ( $\sim 430 \mathrm{HV}$ whatever the load) as a function of the applied load. The indentation depth was always much greater or of the same range than the nitrided layer depth, so the measured hardness cannot be considered as simply belonging to the nitrided layer alone. The sample thermally treated in $\mathrm{N}_{2} / \mathrm{H}_{2}$ (i.e. without plasma nor PBII) shows a very light softening of the surface. All the other nitrided samples exhibit an important increase of the surface microhardness. This strengthening of the surface will allow an important reduction of the surface wear in tribology solicitations. By increasing the PBII high voltage from 0.02 to $15 \mathrm{kV}$, the nitriding leads to a lower surface microhardness. With $20 \mathrm{kV}$, the results are similar to those of the $15 \mathrm{kV}$ one. The highest hardening is obtained with $\mathrm{N}_{2} / \mathrm{H}_{2}$ plasma, at floating potential or without high voltage application $(0.02 \mathrm{kV})$.

\subsection{X-ray diffraction}

The virgin D30-CoCrMo presents well-defined peaks (111) and (200) of diffraction corresponding to the (111) and (200) of the face centred cubic structure, called $\gamma$ phase [7] or $\alpha$ phase [10]. As presented in Fig. 2, after the PBII nitriding, the diffractogram is composed of the initial CoCrMo peaks, with higher intensity as the PBII high voltage keeps increasing from 0.02 to $15 \mathrm{kV}$, indicating the presence of either a thinner or a less dense surface nitrided layer. The ratio $(111) /(200)$ is more or less conserved in the bulk core.

Two broad peaks around $2 \theta=40.5^{\circ}$ and $2 \theta=45.5^{\circ}$ are characteristic of the "expanded" f.c.c. $\gamma_{\mathrm{N}}$ structure, that is the original f.c.c. structure swelled by the insertion of nitrogen in the octahedral sites $[7,10]$. Compared to the original D30-CoCrMo $\gamma$ peaks, the (111) peak

Table 1

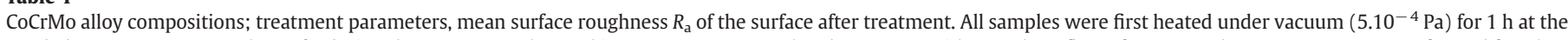

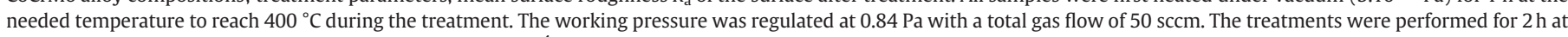
$400{ }^{\circ} \mathrm{C}$. The samples were then cooled under vacuum $\left(5 \cdot 10^{-4} \mathrm{~Pa}\right)$. The two asterisks $\left.{ }^{* *}\right)$ indicate a non-relevant parameter for the sample.

\begin{tabular}{|c|c|c|c|c|c|c|c|}
\hline Sample name & Substrate & Gas & Plasma power & Polarization & Pulse length, frequency & Dose $\left(\mathrm{n} / \mathrm{cm}^{2}\right)$ & $R_{\mathrm{a}}(\mathrm{nm})$ \\
\hline D30-CoCrMo & \multicolumn{6}{|c|}{ Composition (at.\%): Co: 63.7 - Cr: 29.8 - Mo: 3.35 - Si: 1.2 - Mn: 0.85 - C: 0.3 - N: 0.8} & 6 \\
\hline D15-CoCrMo & \multicolumn{6}{|c|}{ Composition (at.\%): Co: 63.5 - Cr: 30.8 - Mo: 3.4 - Si: 1.5 - Mn: 0.6 - C: 0.2} & 4 \\
\hline D30-0.02 kV & D30 & $\mathrm{N}_{2}$ & $700 \mathrm{~W}$ & $-0.02 \mathrm{kV}$ & ** $\quad$ - & ** & 190 \\
\hline D30-5 kV & D30 & $\mathrm{N}_{2}$ & $700 \mathrm{~W}$ & $-5 \mathrm{kV}$ & $40 \mu \mathrm{s}-1000 \mathrm{~Hz}$ & 7.7E17 & 116 \\
\hline D30-10 kV & D30 & $\mathrm{N}_{2}$ & $700 \mathrm{~W}$ & $-10 \mathrm{kV}$ & $25 \mu \mathrm{s}-500 \mathrm{~Hz}$ & 7.1E17 & 67 \\
\hline D30-15 kV & D30 & $\mathrm{N}_{2}$ & $700 \mathrm{~W}$ & $-15 \mathrm{kV}$ & $20 \mu \mathrm{s}-200 \mathrm{~Hz}$ & $10.5 \mathrm{E} 17$ & 23 \\
\hline D30-20 kV & D30 & $\mathrm{N}_{2}$ & $700 \mathrm{~W}$ & $-20 \mathrm{kV}$ & $20 \mu \mathrm{s}-200 \mathrm{~Hz}$ & $8.6 \mathrm{E} 17$ & 35 \\
\hline D15-0.02 kV-N2 & D15 & $\mathrm{N}_{2}$ & $700 \mathrm{~W}$ & $-0.02 \mathrm{kV}$ & $* *$ & $* *$ & 21 \\
\hline D15-0.02 kV-N2/H2 & D15 & $\begin{array}{l}\mathrm{N}_{2}: 60 \% \\
\mathrm{H}_{2}: 40 \%\end{array}$ & $700 \mathrm{~W}$ & $-0.02 \mathrm{kV}$ & $* *$ & $* *$ & 193 \\
\hline D15-FPPAN-N2/H2 & D15 & $\begin{array}{l}\mathrm{N}_{2}: 60 \% \\
\mathrm{H}_{2}: 40 \%\end{array}$ & $700 \mathrm{~W}$ & floating & $* *$ & $* *$ & 189 \\
\hline D15-Therm & D15 & $\begin{array}{l}\mathrm{N}_{2}: 60 \% \\
\mathrm{H}_{2}: 40 \%\end{array}$ & NO & $* *$ & $* *$ & $* *$ & 4 \\
\hline
\end{tabular}


a

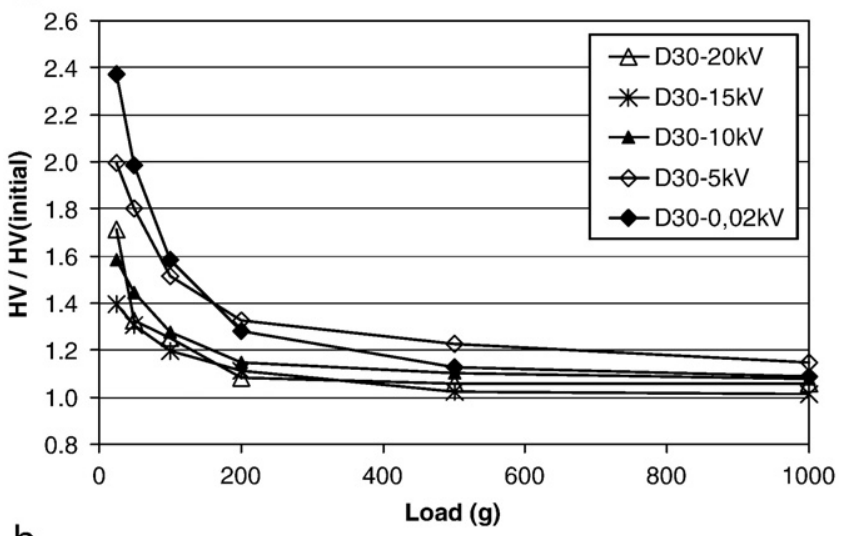

b

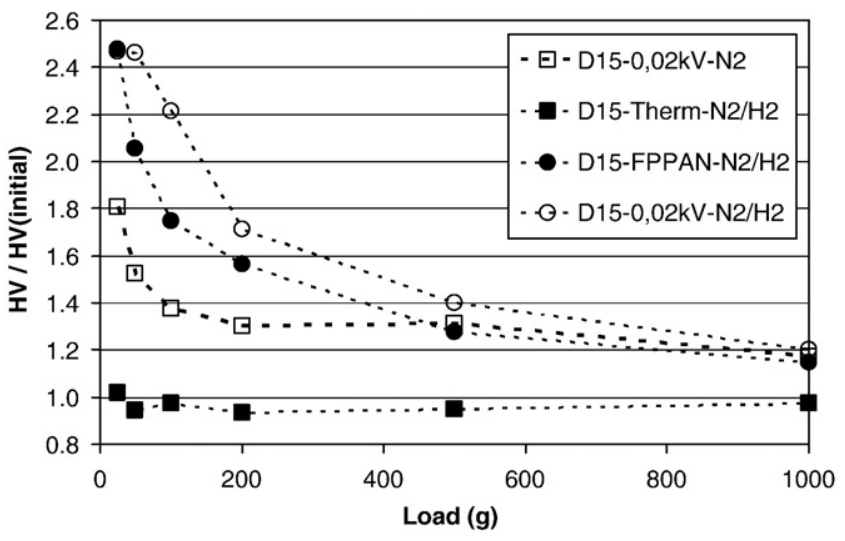

Fig. 1. Vickers microhardness improvement versus applied load. a) D30 samples treated by PBII in N2 plasma; b) D15 samples treated without plasma in N2/H2, with $\mathrm{N} 2 / \mathrm{H} 2$ plasma at floating potential (FPPAN) or with $\mathrm{N} 2 / \mathrm{H} 2$ and $\mathrm{N} 2$ at $0.02 \mathrm{kV}$. The HV values were obtained with at least 4 different measurements, with accuracy of about $20 \%$ $(25 \mathrm{~g}), 15 \%(50 \mathrm{~g})$ or less than $10 \%$ (100 $\mathrm{g}$ to $1000 \mathrm{~g})$.

has shifted of about $3^{\circ}$ and the (200) peak of about $5.5^{\circ}$. This is corresponding to an increase of about $8 \%$ of the (111) interplanar distance and of more than $11 \%$ of the (200) one. This modification of the cell parameters is often linked to the nitrogen content by means of Vegard's law for instance. Following this argument, the (200) oriented grains would then have a higher nitrogen content than the (111) ones $[7,10]$. However, the residual compressive stress induced by the incorporation of nitrogen have to be taken into account and they don't have the same influence on the different grains due to the orientation

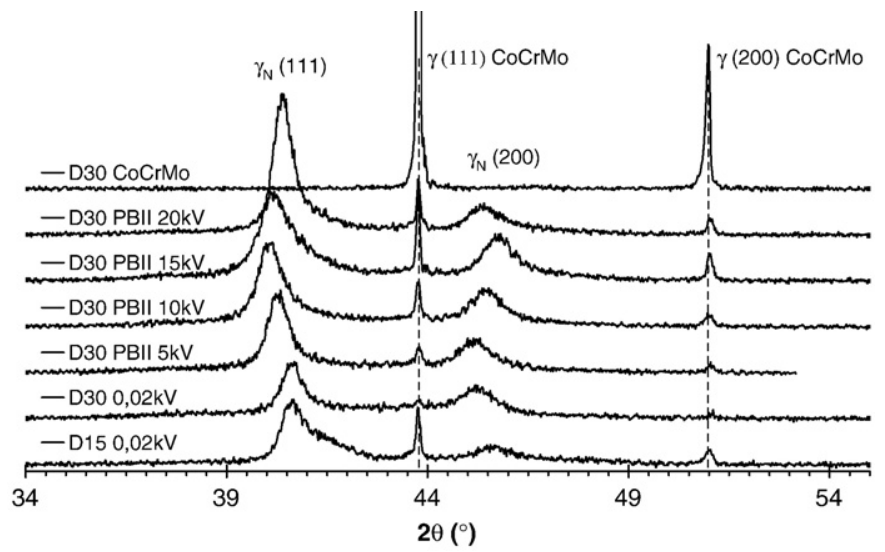

Fig. 2. X-ray diffraction patterns obtained on the D30 samples and on the D15-0.02 kV-N2 sample for comparison. dependence of the elastic constants [24]. The asymmetry of the two $\gamma_{\mathrm{N}}$ peaks is usually related to the gradient of nitrogen composition in the $\gamma_{\mathrm{N}}$ layer, which induces a different level of deformations of the cells in the different grains.

The shift of the $\gamma_{N}$ (111) peak seems to depend on the PBII high voltage: it increases from 0.02 to $10-15 \mathrm{kV}$ and then decrease slightly till $20 \mathrm{kV}$. Simultaneously, the intensity of the $\gamma_{\mathrm{N}}$ (111) peak is continuously increasing with the high voltage. On the contrary, the shift of the $\gamma_{N}$ (200) peak is maximum for the D30-0.02 kV and D30$5 \mathrm{kV}$ samples and is then decreasing till $15 \mathrm{kV}$, before increasing again with the $20 \mathrm{kV}$ sample. The intensity follows an inverse trend, being maximal for $15 \mathrm{kV}$ specimen.

The D15-CoCrMo diffractogram is significantly different from that of the D30-CoCrMo by the presence of the hexagonal $\varepsilon$ phase (peak $\varepsilon$ (101)) in addition to the f.c.c. $\gamma$ phase (Fig. 3). The relative intensities between the (111) and (200) peaks are similar to the ones obtained in the D30-CoCrMo.

The D15 sample treated by thermal (without plasma) activation in an $\mathrm{N}_{2} / \mathrm{H}_{2}$ atmosphere reveals a completely similar diffraction pattern as that of the original one: no nitrogen incorporation has occurred. One can notice that the microstructure (relative parts of $\gamma$ and $\varepsilon$ phases) has not been modified at all by the thermal treatment (heating at $400{ }^{\circ} \mathrm{C}$ for $2 \mathrm{~h}$ ).

As with PBII nitriding of D30-CoCrMo, the D15-CoCrMo plasma nitriding in $\mathrm{N}_{2}$ or $\mathrm{N}_{2} / \mathrm{H}_{2}$ produced the formation of the $\gamma_{\mathrm{N}}$ phase, the CoCrMo- $\varepsilon-(101)$ peak having completely disappeared. So the nitrogen incorporation seems to transform the hexagonal phase into the f.c.c. $\gamma_{\mathrm{N}}$ phase. The $0.02 \mathrm{kV}$ and FPPAN treatments in $\mathrm{N}_{2} / \mathrm{H}_{2}$ lead to similar patterns concerning the nature and position of the $\gamma_{\mathrm{N}}$ peaks. However, the $\gamma_{\mathrm{N}}$ (111) peak is significantly weaker for the $0.02 \mathrm{kV}$ sample. Several characteristics of the diffraction patterns of the two samples nitrided in $\mathrm{N}_{2}-\mathrm{H}_{2}$ (FPPAN or $0.02 \mathrm{kV}$ ) are different from the samples nitrided in $\mathrm{N}_{2}$ plasma: firstly, the remaining substrate $\gamma$-(Co,Cr,Mo) peaks are extremely low in intensity, indicating a thicker nitrided layer; secondly, the $\gamma_{N}(111)$ peak becomes less intense than the $\gamma_{N}$ (200) peak. The shift of the peaks is moreover the largest observed for the two kinds of planes (111) and (200). All these observations lead to conclude the presence of a thicker nitride layer with $\mathrm{N}_{2} / \mathrm{H}_{2}$, with likely a higher nitrogen concentration, therefore inducing a more important distortion of the initial cubic cell. Similar rotations of grains and evolution of the surface texturation were already observed on stainless steel and they were related to the induced plastic strain induced by the very high compressive stresses due to the nitrogen incorporation [25]. Another specific feature of the samples treated in $\mathrm{N}_{2} / \mathrm{H}_{2}$ plasma is the "background" signal measured between 37 and $39^{\circ}$. Nitride compounds like $\mathrm{CrN}$ or the $\chi$ phase $(\mathrm{CoCrMo})_{2}+\chi_{\mathrm{N}}$ phase proposed by Öztürk et al. [7] could be responsible for this signal.

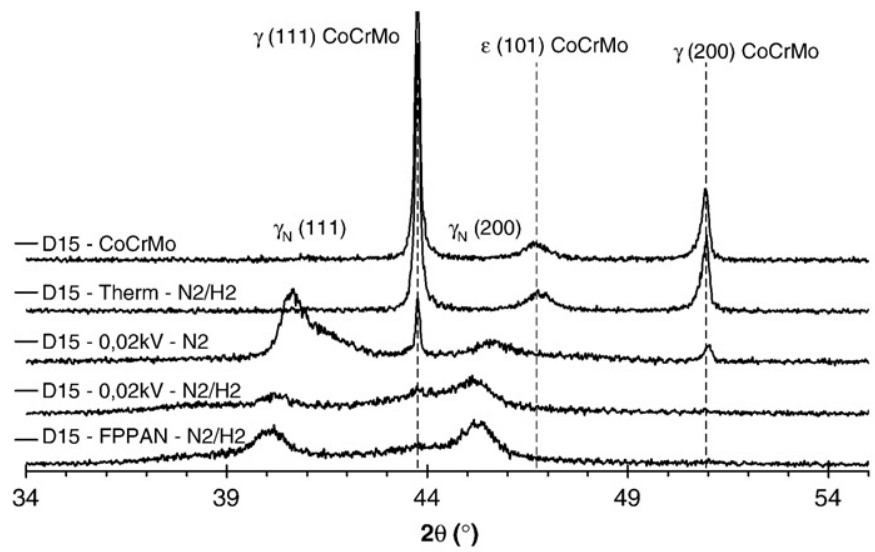

Fig. 3. X-ray diffraction patterns obtained on the D15 samples. 


\subsection{Glow discharge optical emission spectroscopy}

Fig. 4 shows the concentration profiles of the D30-5 kV PBII nitrided sample which is qualitatively similar for all the other nitrided samples, except for the thermally $\mathrm{N}_{2} / \mathrm{H}_{2}$ treated sample which is not nitrided at all. At the top surface (first $200 \mathrm{~nm}$ ) can be seen relatively high concentrations (few at.\%) of oxygen and carbon. They likely correspond to the surface pollution (hydro-oxy-carbonated species) and to some metal oxide which were redistributed by ballistic effect during the GDOES analysis sputtering. No significant difference with the carbon concentration obtained on untreated CoCrMo can be evidenced, indicating that the surface carbon level at the top surface is not relative to a surface contamination during the nitriding process.

A few microns of thick surface nitrided layer contains 30 to 26 at.\% of nitrogen. Below this nitrogen-rich layer, the nitrogen concentration is decreasing very fast to the bulk level. The shape of the nitrogen profile is highly similar to the one obtained on stainless steel after plasma nitriding around $400{ }^{\circ} \mathrm{C}$. It cannot be explained by a simple diffusion-limited growth of the layer and a similar trapping of nitrogen on chromium is likely occurring in CoCrMo too [20,22]. Like in stainless steel or CoCr HS188 alloy [12,15], all the CoCrMo nitrided samples show a higher amount of carbon (from 0.7 to 1 at.\% instead of 0.3 at.\% in the bulk and 0.25 at.\% in the layer) at the interface between the nitrided layer and the bulk. So the nitrogen incorporation is accompanied by a segregation of carbon which seems to be "pushed" by the nitrogen flow.

Fig. 5 presents the profiles of the nitrogen atomic concentrations of the different nitrided samples. First of all, the GDOES profile confirms that the treatment in $\mathrm{N}_{2} / \mathrm{H}_{2}$ without any plasma activation does not lead to any nitrogen incorporation. By comparing the D15-0.02 kV- $\mathrm{N}_{2}$ and the D30-0.02 kV- $\mathrm{N}_{2}$ samples, both treated under the same conditions, a significant difference can be observed, indicating the influence of the original microstructure (presence of the $\varepsilon$ phase and the grains size) of the alloy: if the maximum nitrogen concentrations are similar (about $27-28$ at.\%) in the two samples, the D15 shows a layer of about $2 \mu \mathrm{m}$ thinner than the $2.5 \mu \mathrm{m}$ obtained with the D30. As observed in XRD, the two samples nitrided in $\mathrm{N}_{2} / \mathrm{H}_{2}$ have a higher nitrogen content (up to 33 at.\%) and a thicker nitrided layer than all the other samples treated in $\mathrm{N}_{2}$, whatever the polarization. This result clearly evidences the primordial role of hydrogen in the set of the chemical reactions at the surface governing the nitrogen incorporation.

The D30-0.02 kV-N 2 sample can be considered as the state obtained in PBII by taking into account only what happens between the high voltage pulses, that it for more than $95 \%$ of the treatment time. With the high voltage pulse of $5 \mathrm{kV}$, the nitrided thickness is similar but the concentration of nitrogen is significantly higher than without HV pulses ( +2.5 at.\%), almost reaching the level obtained with $\mathrm{N}_{2} / \mathrm{H}_{2}$. By increasing the high voltage till $15 \mathrm{kV}$, the nitrided thickness is decreasing (because of sputtering) but the surface

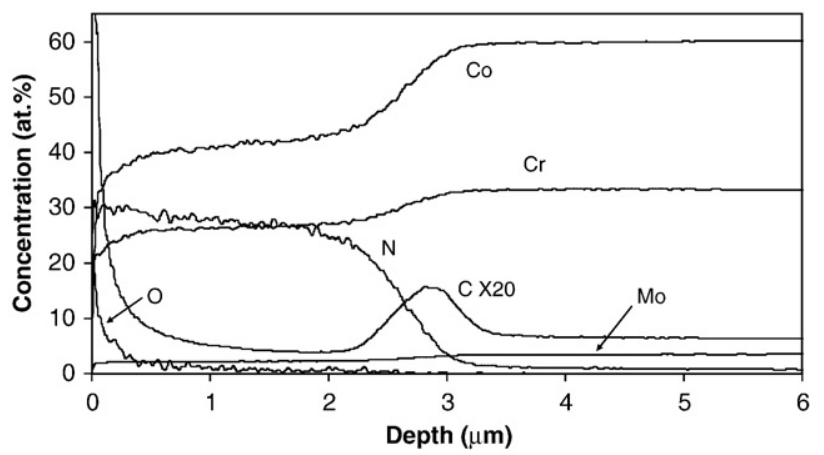

Fig. 4. GDOES atomic concentration profiles obtained on PBII nitrided D30-CoCrMo $\left(5 \mathrm{kV}-400{ }^{\circ} \mathrm{C}-\mathrm{N} 2\right)$.
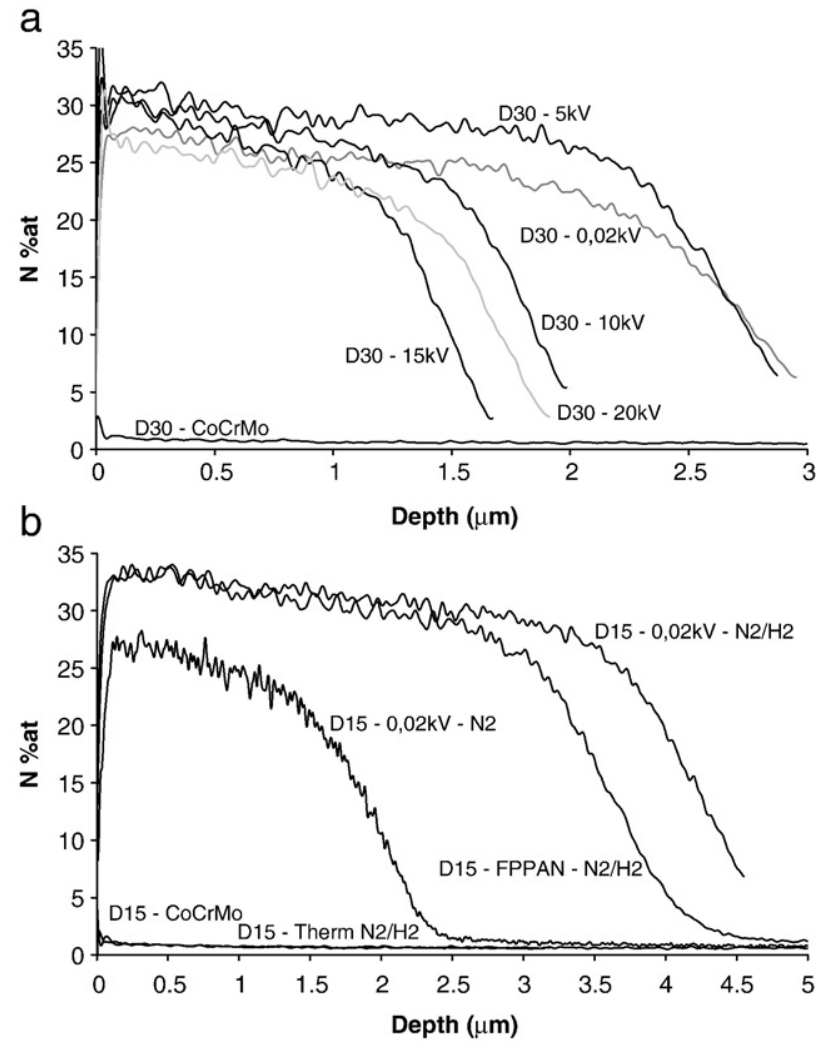

Fig. 5. GDOES nitrogen atomic concentration profiles obtained on a) on D30-CoCrMo nitrided in pure $\mathrm{N}_{2}$ b) on nitrided D15-CoCrMo.

concentration remains at about 30 at.\%. With $20 \mathrm{kV}$ pulses (D30$20 \mathrm{kV}$ ), the nitrogen concentration has decreased below that of the D30-0.02 kV-N $\mathrm{N}_{2}$ sample. The thickness is moreover slightly thicker than with $15 \mathrm{kV}$, as previously indicated by the lower $\gamma$ peaks in XRD: the slightly higher dose and a possible higher sputtering yield with $15 \mathrm{kV}$ pulses may be responsible of this thicker nitrided layer at $20 \mathrm{kV}$ than at $15 \mathrm{kV}$. However, a higher sputtering at $15 \mathrm{kV}$ would also lead to lower nitrogen content at the surface because nitrogen is significantly preferentially sputtered than the alloy metals.

Another interesting feature of the GDOES profiles is the slope of the nitrogen concentration drop between the nitrided layer and the bulk: this slope is similar for all the high voltage (5 to $20 \mathrm{kV}$ ) PBII nitrided samples whereas it is less pronounced for all the FPPAN and $0.02 \mathrm{kV}$ samples, whatever the nitrogen surface concentration value. In the nitriding model of stainless steel proposed in the literature $[19,21,22]$, this slope is related to the equilibrium solubility product $\mathrm{K}_{\mathrm{CrN}}$ commanding the nitrogen trapping at $\mathrm{Cr}$ atoms. A large value of $\mathrm{K}_{\mathrm{CrN}}$ signifies that high concentrations of dissolved nitrogen and of $\mathrm{Cr}$ atoms are necessary to trap nitrogen. The higher the $\mathrm{K}_{\mathrm{CrN}}$, the more gradual is the transition between the nitrided zone and the bulk. So, in our case, the ion bombardment during the PBII treatment seems to modify this characteristic.

\subsection{Surface roughness}

Table 1 indicates the surface roughness. In the same way, the roughness increases with the nitrided thickness; it is most likely due to the different swelling of the grains (depending on their orientation and on their nitrogen content) instead of the ion sputtering. 


\section{Discussion}

The characterization of CoCrMo nitrided at $400{ }^{\circ} \mathrm{C}$ for $2 \mathrm{~h}$ in $\mathrm{N}_{2}$, in $\mathrm{N}_{2} / \mathrm{H}_{2}$, with or without plasma activation and with or without high voltage negative pulses (PBII) allows to conclude on the possible mechanisms determining the nitrogen incorporation.

The sample exposed to nitrogen/hydrogen mixture at $400{ }^{\circ} \mathrm{C}$ without plasma activation has not been nitrided at all. This is relevant to the high corrosion resistance properties of the CoCrMo alloys as long as no chromium nitride can be formed. Indeed, at $400{ }^{\circ} \mathrm{C}$, the thermal activation of the $\mathrm{N}_{2}$ dissociation is poorly efficient to produce atomic nitrogen in solid state available for diffusion. Moreover the electrochemical reduction power of $\mathrm{H}_{2}$ is not sufficient at $400{ }^{\circ} \mathrm{C}$ to reduce the $\mathrm{Cr}-\mathrm{O}$ bounds of the passivation oxide barrier $\left(\mathrm{Cr}_{2} \mathrm{O}_{3}\right)$ and then to allow a further diffusion of atomic N [13].

With the RF excitation of the gas creating activated and reactive species like ions and radicals, incorporation of nitrogen is achieved in solid solution in the f.c.c. metal structure, without $\mathrm{CrN}$ phase formation in most cases. Indeed, atomic nitrogen in the solid state can be obtained at the surface by the dissociation of plasma $\mathrm{N}_{2}^{*}$ radicals or ions which are much more unstable than molecular $\mathrm{N}_{2}$. Therefore nitriding is made possible although partially limited by diffusion through the surface oxide: the top surface concentration in oxygen is indeed significantly higher (about 60 at.\%) with samples D15-0.02 kV$\mathrm{N}_{2}$ and D30-0.02 kV-N $\mathrm{N}_{2}$ than those in the other ones ( 30 at.\% in PBII or $\mathrm{N}_{2} / \mathrm{H}_{2}$ samples). So an oxide layer of a few nanometres still exists in this case and limits the nitrogen content available just below the surface oxide for the deeper diffusion.

When using $\mathrm{NH}_{3}$ for nitriding of stainless steels, the use of additional hydrogen, by reducing the partial pressure of $\mathrm{NH}_{3}$, is to reduce the nitrogen activity in the solid state, that is the available diffusing nitrogen at the surface $[21,22]$. By consequence, the maximum (surface) nitrogen concentration in the layer is reduced and the nitrided thickness is lower. In our case, when no high voltage is applied, the use of hydrogen in the plasma has an opposite effect as the obtained surface concentrations and thicknesses are higher. So the reduction of the partial pressure of $\mathrm{N}_{2}$ is not the main effect of the addition of hydrogen in the reactive plasma and it is counterbalanced by another effect favourable to the nitrogen incorporation. Using hydrogen does likely not favour the $\mathrm{N}_{2}$ dissociation at the surface. However, it allows, with plasma activation of the $\mathrm{H}_{2}$ molecules, the reduction of the surface oxide and the oxygen elimination. Then it favours higher nitrogen content available just below the surface for inward deep diffusion in the alloy.

By using PBII high voltage $(<15 \mathrm{kV})$ pulses with $\mathrm{N}_{2}$ plasma, higher nitrogen contents are achieved, especially close to the surface. This can be explained by the ion bombardment: implantation bringing additional nitrogen below the surface oxide (projected range of few $\mathrm{nm}$ following SRIM calculations). The amount of implanted nitrogen $\left(\sim 8.10^{17} \mathrm{~N} / \mathrm{cm}^{2}\right)$ is indeed of the same range of order than the difference between the nitrogen amount in the D30-5 kV (30 at.\%) and the D30-0.02 kV (27 at.\%), without taking into account backscattered ions (about 10\% of the ions following SRIM simulation) nor sputtering. Independently of the brought amount, the higher nitrogen concentration then available at the surface would lead to a deeper diffusion. By its supplementary energy supply, the ion bombardment may assist, at the surface, the chemical reaction of the $\mathrm{N}_{2}$ dissociation and the atomic nitrogen absorption. Another important effect is the sputtering of the surface that may be in one hand favourable to the nitrogen incorporation by getting rid of the surface oxide (like with hydrogen).

On the other hand, the variation of the high voltage of the PBII pulses leads to variation of the nitrided layer thickness. This result is relevant to the sputtering evolution with the ion energy: with $5 \mathrm{kV}$, the sputtering of the nitrided layer is low enough to be more or less compensated by the faster diffusion induced by the ion implantation and surface oxide elimination. So the nitrided layer is richer in nitrogen and of the same thickness than without high voltage pulse (D30-0.02 kV). This difference is responsible of the shift of the two $\gamma_{\mathrm{N}}$ peaks towards low angles. By increasing the high voltage to 10 and $15 \mathrm{kV}$, the sputtering becomes much higher than the diffusion enhancement; the final thickness is then lower than with $5 \mathrm{kV}$ pulses. With $20 \mathrm{kV}$ pulses, the sputtering is slightly lower than with $15 \mathrm{kV}$ pulse (following SRIM results), then leading to a thicker nitrided layer. The lower nitrogen concentration might be due to an evolution of a more preferential sputtering of nitrogen and have to be confirmed by future experiments at higher energy. The modifications of the $\gamma_{\mathrm{N}}$ peaks with the high voltage are not so evident to understand because of the contradictory effects of the ion bombardment. By increasing the high voltage from $5 \mathrm{kV}$ to $15 \mathrm{kV}$, the $\gamma_{\mathrm{N}}$ (111) peak still shifts toward low angles. This would indicate a higher compressive stress or a higher nitrogen content in the (111) oriented grains. This is surprising because the nitrided layer was shown to be thinner and to have a globally lower nitrogen content. A sputtering yield dependent of the grains orientation and favouring the (111) grains may explain such a result. On the contrary, the $\gamma_{\mathrm{N}}(200)$ peak positions have an opposite trend of the $\gamma_{\mathrm{N}}(111)$. They are then coherent with the thickness and content evolutions.

The apparent influence of the PBII on the slope of the nitrogen concentration at the interface nitrided layer/bulk (so on the $\mathrm{K}_{\mathrm{CrN}}$ value) is difficult to link to the ion bombardment. Complementary experiments at lower or higher energy and a simulation taking into account the implantation, the sputtering, the induced modifications of the diffusion coefficient, the trapping and the influence of the compressive stress would be necessary to understand this effect.

\section{Conclusion}

CoCrMo were nitrided for $2 \mathrm{~h}$ at $400{ }^{\circ} \mathrm{C}$ in $\mathrm{N}_{2}$ or $\mathrm{N}_{2} / \mathrm{H}_{2}$ with or without plasma assistance and with or without high voltage pulses (PBII); up to 30 at.\% of nitrogen can be introduced in the CoCrMo alloys on few microns, inducing an important increase in the surface microhardness. It was demonstrated that a plasma activation of the reactive atmosphere $\left(\mathrm{N}_{2}\right.$ or $\left.\mathrm{N}_{2} / \mathrm{H}_{2}\right)$ was necessary to allow the $\mathrm{N}_{2}$ dissociation and subsequent nitrogen incorporation. With hydrogen reducing the surface oxide, the nitriding is significantly more efficient than with pure $\mathrm{N}_{2}$, by allowing a thicker layer and higher nitrogen content. Using pulsed high voltage polarization improved the nitrogen incorporation by implanting a consequent amount of nitrogen in the subsurface and sputtering the surface oxide. However, depending on the high voltage, a competitive phenomenon of sputtering can be responsible for a thinner nitrided layer with lower $\mathrm{N}$ contents.

\section{Acknowledgements}

TIPSAN (Turkey) is thanked for providing surgical grade CoCrMo alloys. Part of this work was realized with financial support of the Bosphore PHC Program of the French and Turkish Foreign Affairs Ministries.

\section{References}

[1] M. Long, H.J. Rack, Biomaterials 19 (1998) 1621

[2] P. Pascal, Nouveau Traité de Chimie Minérale, Tome XX Alliages métalliques, 1964.

[3] M.A. Wimmer, J. Loos, R. Nassutt, M. Heitkemper, A. Fischer, Wear 250 (2001) 129.

[4] K. Peters, H. Schmidt, R.E. Unger, G. Kamp, F. Pröls, B.J. Berger, C.J. Kirkpatrick, Mol. Cell. Biochem. 270 (2005) 157.

[5] M.G. Shettlemore, K.J. Bundy, Biomaterials 22 (2001) 2211.

[6] J.M. Williams, L. Riester, R. Pandey, A.W. Eberhart, Surf. Coat. Technol. 88 (1996) 132

[7] O. Öztürk, U. Türkan, A.E. Eroglu, Surf. Coat. Technol. 200 (2006) 5687.

[8] C. Díaz, J. Lutz, S. Mändl, J.A. García, R. Martínez, R.J. Rodríguez, Nucl. Instrum. Methods Phys. B 267 (2009) 1630.

[9] R. Wei, T. Booker, C. Rincon, J. Arps, Surf. Coat. Technol. 186 (2004) 305. 
[10] B.R. Lanning, R. Wei, Surf. Coat. Technol. 186 (2004) 314.

[11] A. Çelik, Ö. Bayrak, A. Alsaran, İ. Kaymaz, A.F. Yetim, Surf. Coat. Technol. 202 (2008) 2433.

[12] J. Chen, X.Y. Li, T. Bell, H. Dong, Wear 264 (2007) 157.

[13] J. Lutz, S. Mändl, Nucl. Instrum. Methods Phys. B 267 (2009) 1522.

[14] J. Lutz, A. Lehmann, S. Mändl, Surf. Coat. Technol. 202 (2008) 3747.

[15] J. Lutz, J.W. Gerlach, S. Mändl, Phys. Status Solidi A 205 (2008) 980.

[16] D. Ikeda, M. Ogawa, Y. Hara, Y. Nishimura, O. Odusanya, K. Azuma, S. Matsuda, M. Yatsuzuka, A. Murakami, Surf. Coat. Technol. 156 (2002) 301.

[17] Y. Sun, T. Bell, Mater. Sci. Eng. A224 (1997) 33.

[18] M. Gouné, T. Belmonte, J.M. Fiorani, S. Chomer, H. Michel, Thin Solid Films 377378 (2000) 543.
[19] R.E. Schacherl, P.C.J. Graat, E.J. Mittemeijer, Metall. Mater. Trans. A 35A (2004) 3387.

[20] G. Abrasonis, J.P. Rivière, C. Templier, L. Pranevicius, N.P. Barradas, J. Appl. Phys. 97 (2005) 124906.

[21] T. Christiansen, M.A.J. Sommers, Metall. Mater. Trans. A 37A (2006) 675.

[22] T. Christiansen, M.A.J. Sommers, Defects Diffus. Forum 258-260 (2006) 378.

[23] L. Marot, M. Drouet, F. Berneau, A. Straboni, Surf. Coat. Technol. 156 (2002) 155

[24] T. Christiansen, M.A.J. Sommers, Scripta Mater. 50 (2004) 35

[25] M. Drouet, J.C. Stinville, P. Villechaise, J.P. Rivière, C. Templier, Eur. Phys. J. Appl. Phys. 43 (2008) 349. 